\title{
Opportunities and Obstacles to Aquaculture in Florida ${ }^{1}$
}

\author{
Edward Camp, Taryn Garlock, and James Anderson²
}

\section{Abstract}

Aquaculture is growing worldwide, but in Florida it has yet to meet its potential. Further, some aquaculture ventures, especially those associated with finfish-for-consumption mariculture (marine aquaculture), have struggled to succeed in Florida. To better understand why this might be, we worked with a group of experienced aquaculturists and aquaculture specialists to describe the perceived requirements of successful aquaculture. The insights from these specialists are placed in the context of current international literature about aquaculture and described in this document. This document is intended to provide information helpful for potential aquaculturists seeking to better anticipate potential pitfalls to avoid, as well as to governance agencies interested in developing regulatory frameworks that better encourage aquaculture investment.

\section{Background on Aquaculture and Purpose of This Document}

Globally, aquaculture provides more than half of the fish humans consume and is the fastest-growing animal food industry (Moffitt and Cajas-Cano 2014; Ottinger et al. 2016). Aquaculture can increase the diversity and potentially the resilience of food systems, while often requiring less energy or freshwater than other animal-food sources (Hilborn et al. 2018). While recent studies have found the United States to have great potential for growth in aquaculture, this potential is largely unrealized, and currently the United States imports about $90 \%$ of its seafood (Kaiser et al. 2011; Knapp and Rubino 2016; Lester et al. 2018). This has motivated the US Department of Commerce to encourage increased aquaculture production in the United States. Accordingly, states like Florida that have extensive coastlines and access to necessary fresh and saltwater resources are interested in motivating greater investment in sustainable aquaculture. This document describes some of the opportunities and obstacles that characterize aquaculture in Florida. There are two primary, intended uses of this document: (1) to provide

1. This document is FA221, one of a series of the School of Forest Resources and Conservation, Program in Fisheries and Aquatic Sciences, UF/IFAS Extension. Original publication date February 2020. Visit the EDIS website at https://edis.ifas.ufl.edu for the currently supported version of this publication.

2. Edward Camp, assistant professor, School of Forest Resources and Conservation; Taryn Garlock, postdoctoral associate, Institute for Sustainable Food Systems; and James Anderson, professor, Food and Resource Economics Department, and director, Institute for Sustainable Food Systems; UF/IFAS Extension, Gainesville, FL 32611.

The information in this document was created following a small Florida Aquaculture "Think Tank" on April 27, 2018 that was co-hosted by the Florida Department of Agriculture and Consumer Services (FDACS) and the UF/IFAS Institute for Sustainable Food Systems (ISFS). The purpose of this meeting was to understand some industry, governance, and research perspectives regarding past and future aquaculture in Florida. Participants included: Carlos Martinez (Horse Creek Aquaculture Farm, Arcadia, FL); Sergio Alvarez (FDACS); Sebastian Belle (Maine Aquaculture Association); Frank Asche (UF/IFAS); Kal Knickerbocker (FDACS, dir. aquaculture); Portia Sapp (FDACS asst. dir., aquaculture); Cortney Ohs (UF/FAS Indian River REC); James Anderson (UF/IFAS director ISFS); Dennis Peters (Gulf South Research Corp., Niceville, FL); Kevan Main (dir. Mote Aquaculture Research Park, Sarasota, FL); Neil Sims (co-CEO Kampachi Farms LLC); Lisa Conti (FDACS, deputy commissioner and chief scientist); Joe Cardenas—(CEO Aquaco Farms, Ft. Pierce, FL); Geno Evans (Evans Fish Farm, Pierson, FL); Darryl Jory (consultant and editor, Aquaculture Advocate).

The Institute of Food and Agricultural Sciences (IFAS) is an Equal Opportunity Institution authorized to provide research, educational information and other services

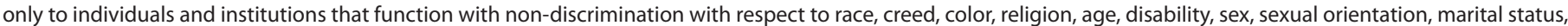

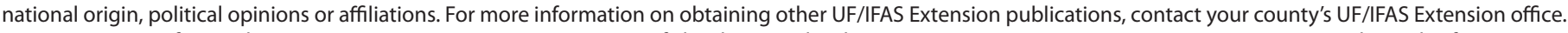
U.S. Department of Agriculture, UF/IFAS Extension Service, University of Florida, IFAS, Florida A \& M University Cooperative Extension Program, and Boards of County Commissioners Cooperating. Nick T. Place, dean for UF/IFAS Extension. 
aquaculturists and potential aquaculturists, especially those in Florida, with information about the likely impediments to successful ventures, and (2) to provide information to governance institutions like management agencies about what regulations may cause unintended negative effects on the growth of Florida aquaculture. For both of these purposes, this document provides perspectives from people already in the industry and from the broader scientific literature.

\section{Overview of the Current State of Aquaculture in Florida and Beyond State of Aquaculture: United States and the World}

The world will have nine billion people who will need food and fresh water by 2050, but more importantly for aquaculture, wealth, and with wealth, seafood consumption per capita, will increase. The United States has not yet realized its great potential to produce farmed seafood (Kapetsky et al. 2013). The US seafood supply could be increased in two different ways: (1) import more (mostly farmed) seafood from other countries, or (2) grow more seafood domestically (Knapp and Rubino 2016). Up until now, the United States has mostly chosen to import more seafood, especially from developing nations (Kaiser et al. 2011). This choice creates a seafood "trade deficit" that may inadvertently encourage seafood production in places where there are more concerns about environmental management, disease management practice (antibiotic use), potential labor exploitation, fraud, quality control, political uncertainty, and risk of nonnative species introductions.

\section{State of Aquaculture: Florida}

Florida is a major aquaculture producer in the United States and is among the leading states ( $5^{\text {th }}$ in 2013) in terms of sales from aquaculture; it likely has the potential to grow even more. Florida's coastline is second only to Alaska's in length, with substantial state-controlled waters (extending 9 nautical miles from shore) along the Gulf Coast. Aquaculture in Florida is diverse, and nearly $70 \%$ of aquaculture sales are comprised of tropical ornamental fish (the largest sector in the state), alligator farming, and shellfish farming (mostly hard clams). Finfish aquaculture for food is a sector characterized by great opportunity but few successes. The Florida Department of Agriculture and Consumer Services (FDACS) currently manages aquaculture regulations. Specifically, FDACS requires the registration of aquaculture facilities, adherence to mandatory best management practices and, where applicable, leases public submerged lands (including substrate) and water column for the purpose of aquaculture. The FDACS Division of Aquaculture has certified over 1000 registered aquaculture operations and over 700 total submerged land leases.

\section{Perspectives on Causes of Aquaculture Failure and Success}

The aquaculture specialists we spoke with were asked to complete two surveys. The first survey was about why aquaculture ventures might fail, and the second survey was about what caused aquaculture ventures to succeed. For each survey, participants were supplied a list of 21 potential factors that might influence aquaculture venture failure or success. First, participants ranked the factors they thought led to aquaculture failure. The results of the most commonly described reasons for failure and success are described in Figures 1 and 2.

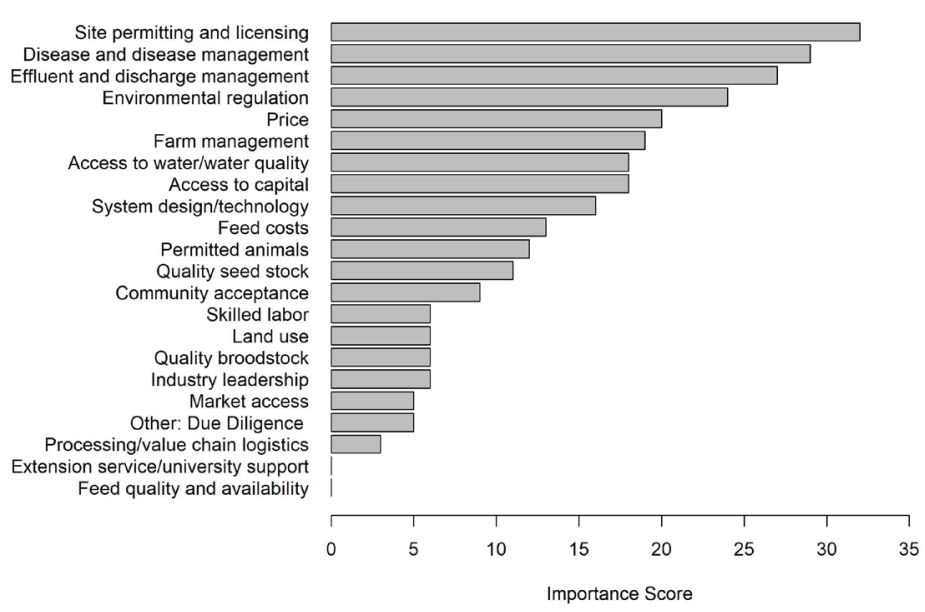

Figure 1. Ranking of factors associated with aquaculture failures. Credits: Taryn Garlock

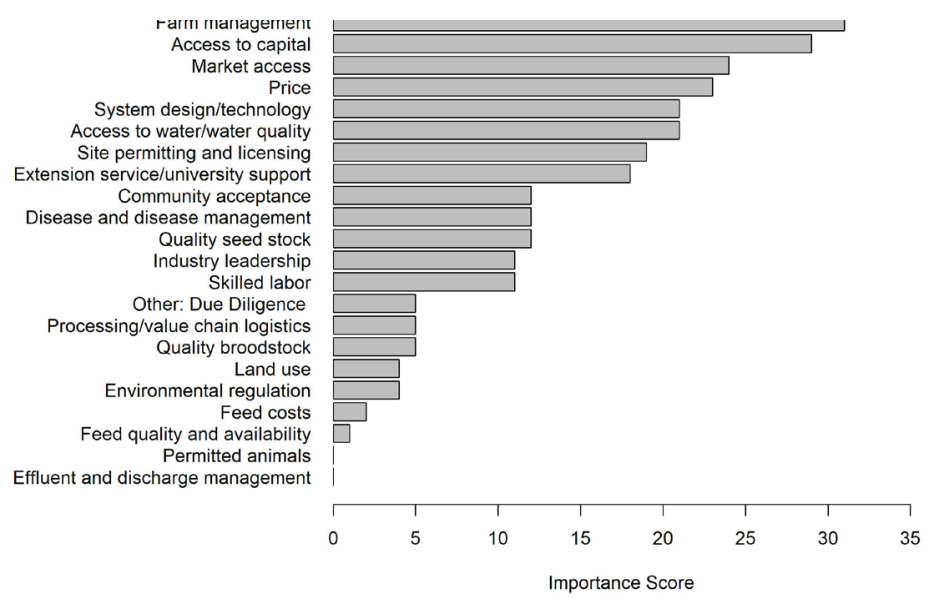

Figure 2. Ranking of factors associated with aquaculture success. Credits: Taryn Garlock 


\section{How Governance Policy Is Perceived to Affect Florida Aquaculture}

Five themes emerged regarding how governance policy was likely to affect aquaculture more broadly and in ways specific to Florida, and these were generally also supported by recent scientific literature.

\section{Overly restrictive policies are commonly thought to cause failures, and sometimes they do.}

Poorly designed or overly restrictive governance is often blamed for aquaculture firm problems and failures. For example:

- The scientific literature describes that at the federal level, regulations are likely stifling offshore aquaculture in the United States (Kaiser et al. 2011; Knapp and Rubino 2016). The regulations themselves may be overly restrictive (e.g., maximum limits on how much product could be produced, limits on effluent, and short permit or lease durations).

- Participants added that, in Florida, delays (in some cases, years-long) at the state and/or county level had a very negative effect on aquaculture investment. This waiting period translated to greater direct financial costs in terms of required support staff and delayed production, but also has indirect costs because a waiting period makes the business less attractive and more uncertain to investors.

\section{Due diligence and firm-level decision- making are a cause of business failure.}

Despite potential issues with aquaculture regulatory governance, many of the meeting participants, especially industry stakeholders, thought the ultimate determinant of aquaculture success or failure was the aquaculturists' planning for their business-something referred to as "due diligence." For example:

- Meeting participants described examples of Floridaspecific failures caused by a lack of good business models. Common mistakes included not accounting for necessary resources (e.g., appropriate water quality), underestimating production costs, and poor understanding of markets and consumer demand.

- The scientific literature highlights this at a broader scale by emphasizing the substantial planning required for aquaculture success. For example, the state of Maine invested in external consultants to identify in what industries and products the state had a competitive production advantage and then chose to promote investment in mostly these sectors (Knapp and Rubino 2016).

Of course, due diligence envelops many of the other potential causes of failure listed on the survey. For example, all aquaculture operations experience disease issues, but the success of the operation would depend on the planning and investment in biosecurity management to deal with these problems. Similarly, participants noted that successful aquaculturists would take the long permitting process into account while planning. In the end, this meant that those with the time and funds to thoroughly understand, anticipate, and address potential failures before starting an aquaculture operation were those most likely to succeed.

\section{Policy can influence financial feasibility.}

The strain of the aquaculture regulatory process and related need for time and money for planning may mean that the successful aquaculturists will be the ones with the greatest financial resources. More streamlined policies might allow less-wealthy people to participate and a greater number of participants overall to be successful. This was best illustrated via several examples described by meeting participants:

- Successful aquaculture operations should budget substantial resources for the planning and siting stage (including any necessary consultation/contracting). This could avoid much greater costs of having to move to a different site or make other large changes.

- Better regulations by managing agencies enforcing biosecurity could actually limit aquaculture costs, and eventually, failures.

- Management agencies granting longer-term permits and leases could attract more investors to the aquaculture sector by ensuring that investors would be able to recover their investments and accumulate more value which could be used as collateral.

\section{Due diligence extends beyond the individual operation to the association and state.}

Meeting participants thought that the success of some US states at attracting aquaculture investment was because the states engaged in strategic planning. Some examples of components of such a strategic approach for Florida could include: 
- An assessment of the competitiveness of Florida aquaculture in the national/international market, including consideration of supply chain and demand. This could help gauge the scale of aquaculture likely to succeed in Florida.

- An assessment of the types (products) of aquaculture that are likely to be most successful in Florida. For example, high-value products (e.g., half shell oysters, Atlantic salmon) may be more likely to benefit from branding or have profit margins wide enough to support labor costs that are usually greater in the United States than abroad.

- Aquaculture industry associations can work with the state to identify and fill industry lobbying needs, such as attending international aquaculture meetings to encourage international corporation and investment in Florida.

- There should be a discussion among aquaculture associations as well as federal and state agencies regarding aquaculture of native versus non-native species. Current US policies have favored native species with wild-like characteristics and genetics, but it may be that non-native animals that are highly domesticated actually pose a lower risk if they are unlikely to survive upon potential escape (Lorenzen et al. 2012).

\section{The public perception of aquaculture is important.}

The scientific literature includes a number of studies on the "political economies" of aquaculture. This refers to public perceptions of aquaculture (Kelly et al. 2017), which in the US public has typically held more negative views towards aquaculture compared to many other areas (Chu et al. 2010; Knapp and Rubino 2016; Osmundsen and Olsen 2017; Froehlich et al. 2017). This negative perception of aquaculture seems to have been promoted by two groups: (1) environmental organizations, mostly nongovernmental organizations (NGOs) and environmental nongovernmental organizations (eNGOs), and (2) wild-capture fisheries. Some eNGOs may oppose aquaculture because it is perceived to increase environmental degradation (Whitmarsh and Palmieri 2009), whereas fishers typically are concerned that aquaculture may compete with their product and eventually displace them (Natale et al. 2013). What this means for Florida is that the success of aquaculture will ultimately depend on how it is perceived by the public. Progress towards public acceptance may be achieved by:

- Aquaculture associations forging cooperative relationships with wild-capture fisheries. For example, aquaculture associations might partner with wild-capture fisheries to preserve working waterfront access for both aquaculturists and fishers.

- Aquaculturists, management agencies, and outreach personnel spreading information about the potential benefits of aquaculture. For example, recent research findings reveal that many forms of aquaculture can produce protein with lower environmental impact than land-based animal production (Hilborn et al. 2018; Froehlich et al. 2018). This information might shift public perceptions about aquaculture.

\section{Short and Long-Term Actions Needed to Promote Aquaculture in Florida}

Considering the participants' perspectives as well as the literature, there are a number of steps that could lead to increased aquaculture production in Florida.

- Enhance the role of FDACS as lead agency to coordinate the necessary licenses and information from other regulatory bodies and serve as a "one-stop shop."

- Develop state-run aquaculture business incubators and training programs.

- Implement shorter waiting periods on permit applications.

- Increase lease duration.

- Improve the capacity for land grant universities to address the needs of small aquaculture businesses.

- Permit multi-generational stocks for offshore aquaculture.

- Identify viable lease sites that account for county-specific governance.

- Reduce acreage necessary for agricultural exemption.

- Optimize fish feeds, especially for marine land-based recirculating systems.

- Create incentive programs for disease reporting.

- Develop minimum operational standards based on best management practices, and cultivate a valued brand for Florida aquaculture.

- Conduct strategic planning at the state level and create an aquaculture roadmap that includes broad goals and specific, measurable objectives.

- Evaluate opportunity costs of increasing aquaculture production in the state to identify and address potential conflicts and increase public trust. 


\section{Summary}

1. Aquaculture will likely continue to grow globally, but it is not yet clear to what extent the United States, and specifically Florida, will choose to participate in this growth. The physical potential (coastline), technology, and capital exist.

\section{Aquaculture is a business, and successful operations} require due diligence and a viable and carefully crafted business plan. Training programs and business incubators can have a positive effect on business management and operation success and may provide a promising path towards development of a sustainable aquaculture industry in Florida.

3. Governance policies will influence the number, type, and diversity of aquaculture operations that can be expected to succeed. Long waiting periods for permit applications, stringent environmental regulations, and shorter lease terms can deter operations that require significant capital investment. Strategic planning by the industry and the state is necessary to provide direction on the type of aquaculture Florida wants to attract. (If this is not done explicitly, the future of Florida aquaculture will likely be implicitly set by current and future regulations )

\section{An organized and engaged industry is important for} aquaculture's success. Associations need to be organized to lobby for regulatory change, overcome political challenges, and inform public perception of aquaculture. If aquaculture remains unpopular with the public, it may be difficult to develop regulations that motivate broader investment in the sector.

5. Purposeful planning by the state government of Florida, FDACS, and the aquaculture associations of Florida will be necessary to identify directions and specific sectors in which aquaculture can be most successful.

6. Ultimately, the success of aquaculture will depend largely on how it is perceived by the public. Public perception can be purposefully and strategically altered, but this task will in most cases fall to the industry.

7. There are several short- and long-term steps that could increase aquaculture capacity in Florida, many of which can be addressed by governance (specifically FDACS), research, and industry associations.

\section{References}

Chu, J., J. L. Anderson, F. Asche, and L. Tudur. 2010.

"Stakeholders' Perceptions of Aquaculture and Implications for Its Future: A Comparison of the USA and Norway." Marine Resource Economics 25(1): 61-76. https://doi. org/10.5950/0738-1360-25.1.61

Froehlich, H. E., R. R. Gentry, M. B. Rust, D. Grimm, and B. S. Halpern. 2017. "Public Perceptions of Aquaculture: Evaluating Spatiotemporal Patterns of Sentiment around the World." PLoS ONE 12(1): e0169281. doi:10.1371/ journal.pone. 0169281

Froehlich, H. E., C. A. Runge, R. R. Gentry, S. D. Gaines, and B. S. Halpern. 2018. "Comparative Terrestrial Feed and Land Use of an Aquaculture-Dominant World." Proceedings of the National Academy of Sciences 115(20): 5295-5300. https://doi.org/10.1073/pnas.1801692115

Hilborn, R., J. Banobi, S. J. Hall, T. Pucylowski, and T. E. Walsworth. 2018. "The Environmental Cost of Animal Source Foods." Frontiers in Ecology and the Environment 16(6): 329-335. https://doi.org/10.1002/fee.1822

Kaiser, M. J., B. Snyder, and Y. Yu. 2011. "A Review of the Feasibility, Costs, and Benefits of Platform-Based Open Ocean Aquaculture in the Gulf of Mexico." Ocean \& Coastal Management 54(10): 721-730. https://doi.org/10.1016/j. ocecoaman.2011.07.005

Kapetsky, J. M., J. Aguilar-Manjarrez, and J. Jenness. 2013. "A Global Assessment of Offshore Mariculture Potential from a Spatial Perspective." FAO Fisheries and Aquaculture Technical Paper (549) I.

Kelly, R., G. T. Pecl, and A. Fleming. 2017. "Social Licence in the Marine Sector: A Review of Understanding and Application." Marine Policy 81: 21-28. https://doi. org/10.1016/j.marpol.2017.03.005

Knapp, G., and M. C. Rubino. 2016. "The Political Economics of Marine Aquaculture in the United States." Reviews in Fisheries Science \& Aquaculture 24(3): 213-229. https://doi. org/10.1080/23308249.2015.1121202

Lester, S. E., R. R. Gentry, C. V. Kappel, C. White, and S. D. Gaines. 2018. "Opinion: Offshore Aquaculture in the United States: Untapped Potential in Need of Smart Policy." Proceedings of the National Academy of Sciences 115(28): 7162-65. https://doi.org/10.1073/pnas.1808737115 
Lorenzen, K., M. C. Beveridge, and M. Mangel. 2012.

"Cultured Fish: Integrative Biology and Manage-

ment of Domestication and Interactions with Wild

Fish." Biological Reviews 87(3): 639-660. https://doi.

org/10.1111/j.1469-185X.2011.00215.x

Moffitt, C. M., and L. Cajas-Cano. 2014. "Blue Growth:

The 2014 FAO State of World Fisheries and Aquaculture."

Fisheries 39(11): 552-553. https://doi.org/10.1080/0363241

5.2014 .966265

Natale, F., J. Hofherr, G. Fiore, and J. Virtanen. 2013. "Interactions between Aquaculture and Fisheries." Marine Policy 38: 205-213. https://doi.org/10.1016/j.marpol.2012.05.037

Osmundsen, T. C., and M. S. Olsen. 2017. "The Imperishable Controversy over Aquaculture." Marine Policy 76:

136-142. https://doi.org/10.1016/j.marpol.2016.11.022

Ottinger, M., K. Clauss, and C. Kuenzer. 2016. "Aquaculture: Relevance, Distribution, Impacts and Spatial Assessments-A Review." Ocean \& Coastal Management 119: 244-266. https://doi.org/10.1016/j.ocecoaman.2015.10.015

Whitmarsh, D., and M. G. Palmieri. 2009. "Social Acceptability of Marine Aquaculture: The Use of Survey-Based Methods for Eliciting Public and Stakeholder Preferences." Marine Policy 33(3): 452-457. https://doi.org/10.1016/j. marpol.2008.10.003

\section{Acknowledgements}

Lisa Conti and James Anderson organized and conducted the workshop. Lisa Conti, James Anderson, Carlos Martinez, Sergio Alvarez, Sebastian Belle, Frank Asche, Kal Knickerbocker, Portia Sapp, Cortney Ohs, Dennis Peters, Kevan Main, Neil Sims, Joe Cardenas, Geno Evans, and Darryl Jory participated in the workshop. 